\title{
Materialkultur og territorialbevidsthed i Acta
}

\author{
Mag.art., stud.theol. Thomas Lederballe Pedersen
}

Abstract: Material culture either upheld or established by authorities within the Roman empire can be interpreted as vehicles for describing the territorial expansion of Christianity in the Acts of the Apostles. Acts 17:16-34 and 18:24-19:40 display an emphasis on the role played by material culture, notably images in Athens and Ephesus, in defining urban political and cultural centres. Roman material culture also sheds light on the metaphorical meaning of the recurrent expression "the way" in Acts. Acts 8:26-40 provides indications of this, suggesting that the meaning of the expression is informed by the ubiquitous road system in the Roman empire and by the symbolic and metaphorical significance of the roads in describing Roman territory.

Key words: New Testament - Acts of the Apostles - Material Culture Early Church

\section{Imperiet og dets materialkultur}

Materialkulturens rolle i handlingsforløbet i Apostlenes Gerninger har ikke hidtil været genstand for nogen særskilt fortolkning. ${ }^{1}$ I betragtning af den romerske kulturs tydelige islæt i skriftet, sådan som dette element er blevet betonet i nyere eksegese, fremstår spørgsmålet ikke desto mindre relevant. Materialkultur defineres som artefakter, dvs. tillavede genstande, til hvilke der knytter sig funktion eller symbolik, men under alle omstændigheder kulturelt betinget betydning. Selv upåagtede genstande som cowboybukser og milesten bærer iføl-

* Jeg vil gerne takke Troels Engberg-Pedersen og Jesper Tang Nielsen for vejledning i forbindelse med artiklens tilblivelse.

1. Spørgsmålet ignoreres fuldstændig i Luke Timothy Johnson, The Acts of the Apostles, Sacra Pagina 5 (Collegeville, Minn.: The Liturgical Press 1992). HansJosef Klauck er i sin kommentar, Magic and Paganism in Early Christianity. The World of the Acts of the Apostles (opr. 1996, overs. Brian McNeil, Edinburgh: T\&T Clark 2000) i forbindelse med diskussionen af ApG 17 (84) opmærksom på den kultiske praksis, der knytter sig romersk sakralskulptur, men viser ikke in- 
ge materialkultur-forskningen betydninger. Oprindelig forvaltedes denne forskning af discipliner som antropologi og arkæologi, men i det 20. århundredes sidste årtier har flere fag, herunder kunsthistorie og historie, inddraget og bearbejdet materialkultur-forskningens genstandsfelt og metoder. ${ }^{2}$ I den følgende behandling vil jeg især trække på den semiotisk orienterede del af den nyere forskning inden for materialkultur.

For at anskueliggøre det heuristiske perspektiv ved en analyse af materialkultur er det imidlertid nødvendigt med en kort oversigt over dele af Actas nyere receptionshistorie. I henhold til en eksegetisk tradition fra Hans Conzelmanns studier af Lukas-skrifterne, skal Acta læses som en apologia pro ecclesia, en fremstilling af kirken som politisk harmløs for romermagten, på hvis territorium udbredelsen af kirken igennem skriftet finder sted. ${ }^{3}$ Paul Walaskay gjorde i 1983 op med denne tradition ved at fastslå, at forfatterens anliggende snarere har været stik modsat: Der er tale om en apologia pro imperio, som over for de tidlige kristne har skullet demonstrere, at romermagtens repræsentanter, institutioner og retspleje spillede en rolle i forbindelse med befordringen af den kristne forkyndelse. Hos Lukas fremtræ-

teresse for materialkultur som en del af skriftets omverden. I Ben Witherington, III, The Acts of the Apostles. A Socio-Rhetorical Commentary (Grand Rapids, Mich.: William B. Eerdmans Publishing Company 1998) suppleres kommentaren med fotos af lokaliteter og genstande, som nævnes i Acta, sådan at passager i handlingen fremstår som godtgjort ved dokumentationsfotos, men materialkulturelle forhold inddrages ikke i fortolkningen af skriftet. I Bruce J. Malina \& John J. Pilch, Social-Science Commentary on the Book of Acts (Minneapolis: Fortress Press 2008) er det erklærede fokus sociale enheder som kontekst for handlingen i Acta. Forfatterne lader billedmateriale gengive, som viser steder, monumenter el. lign., der omtales i skriftet, for at signalere at dets indhold tilhører "en anden verden" end den moderne læser (11). Også bidragene til den nylige Die Apostelgeschichte im Kontext antiker und frühchristlicher Historiographie, red. J. Frey, C.K. Rothschild, J. Schröter, BZNW 162 (Berlin \& New York: Walter de Gruyter 2010), koncentrerer sig om forskellige tekstbaserede kontekster for forståelsen af Acta. Richard Pervo, Acts. A Commentary, Hermeneia (Minneapolis: Fortress Press 2009), viser til gengæld opmærksomhed over for Paulus' opgør med idolatri i Athen og Efesos (f.eks. 486), men giver ikke dette nogen særlig vægt i sin eksegese.

2. En kortfattet forskningshistorisk oversigt kan findes i Thomas J. Schlereth, "Material Culture and Cultural Research”, Material Culture. A Research Guide, red. Thomas J. Schlereth (Lawrence: The University of Kansas Press 1985), 1-34. Man kan danne sig et indtryk af forskningens nuværende forgreninger i Dan Hicks \& Mary C. Beaudry, "Introduction. Material Culture: a reactionary view", The Oxford Handbook of Material Culture Studies, red. D. Hicks \& M.C. Beaudry (Oxford: Oxford University Press 2010), 1-21.

3. Hans Conzelmann, Die Mitte der Zeit. Studien zur Theologie des Lukas BHTh 17 (Tübingen: J.C.B. Mohr [Paul Siebeck] 1954), 120-4. 
der magthaverne derfor overvejende $\mathrm{i}$ et gunstigt lys. ${ }^{4}$ Dette skal imidlertid ikke forstås sådan, at kristendommen fremstår som forenelig med romerrigets love, repræsentanter eller institutioner, men sådanne instanser kan ifølge Lukas opfattes som anvendelige for kristendommen.

I forlængelse af Walaskays problematisering af det conzelmann'ske forskningsparadigme har Bruce Cassidy studeret det politiske konfliktmateriale i Acta og hæftet sig ved, at det især er under Paulus' konfrontationer med romerske embedsmænd, Lukas markerer, at apostlens mission finder sted inden for en romersk magtsfære. Til forskel herfra er fundamentale betegnere af romersk kultur, f.eks. akvædukter, badeanstalter eller kampsport, helt fraværende fra skriftet og forbliver derfor usynlige i teksten. ${ }^{5}$ Spørgsmålet er imidlertid, om Cassidys nedtoning af disse aspekter holder stik. På den ene side må det medgives, at Lukas ikke eksplicit omtaler dem, men på den anden side udgør bygninger, kunst og vernakulær kultisk praksis, som romerne tillod eller opretholdt, en del af rammen for handlingen i kapitlerne 17 og 18-19. Desuden optræder begrebet "vejen" i skriftets sidste godt og vel to tredjedele som et nøglebegreb i forbindelse med kirkens udbredelse, så på dette punkt knyttes der an til en konkret, materiel genstand.

Vejanlæg, bygninger og kunst tilhører "materialkultur", til forskel fra mundtlig eller tekstbåren kultur. Den romerske materialkulturs identitet er et diskussionsemne blandt arkæologer, som på den ene side hæfter sig ved dens elementers forskelligartethed inden for det vidtstrakte imperium, men på den anden side accepterer, at den havde visse faste bestanddele - eksempelvis villaen eller romervejen. ${ }^{6}$

Jeg skal her argumentere for, at sådanne materialkulturelle bestanddele udgør en forudsætning for forståelse af de nævnte passager i Acta. For det første lader Lukas missionen foregå gennem en symbolsk appropriation af materialkultur under Paulus' virksomhed i Athen og Efesos (ApG 17,16-34 og 18,24-19,40), for her fortrænges eller omdannes den betydning, som knytter sig til eksisterende materialkultur; for det andet bibeholdes konventionelle betydninger ved romer-

4. Paul W. Walaskay, 'And so we came to Rome': The Political Perspective of St Luke (Cambridge: Cambridge University Press 1983), 25.

5. Richard J. Cassidy, Society and Politics in the Acts of the Apostles (Maryknoll, N.Y.: Orbis Books 1987), 118.

6. P.W.M. Freeman, "Romanisation and Roman Material Culture", Journal of Roman Archaeology 6 (1993), 438-45 (444). En fortolkning af den romerske materialkulturs rolle som etnisk markør findes i Gregory D. Woolf, "Becoming Roman, Staying Greek: Culture, Identity, and the Civilising Process in the Roman East”, PCPS 40 (1994), 116-43. 
vejen som kulturelt fænomen i brugen af ordet "vej" i skriftet, ligesom disse betydninger er til stede $\mathrm{i}$ fortællingen om Filips omvendelse af den etiopiske skatmester (8,26-40). Materialkultur optræder altså på to måder i Acta: Som reelle genstande, der indgår i handlingen, og som kontekst for skriftet. I begge henseender bidrager den til dets betydning.

Der synes at være to tendenser i den generelle udforskning af materialkultur. For det første kan der iagttages en metodologi, som behandler materielle genstandes betydningsdannelse ud fra retoriske begreber, såsom "metafor", hvor én tings funktionelle betydninger kan overføres til et andet felt. Kunsthistorikeren Jules Prown hæfter sig ved, at artefakters betydning er knyttet til deres status af metaforer: En genstand betegner i overført forstand en erfaring eller følelse hos den, der benytter den. Erfaringen af eksempelvis en anstødssten retter sig mod egenskaber ved genstanden, som kan overføres til andre emner, og på tilsvarende måder kan materielle genstande have karakter af metonymi eller synekdoke. ${ }^{7}$ For det andet findes en metodologi, ifølge hvilken den retorik-orienterede indfaldsvinkel bør suppleres af en semiotisk bestemmelse af genstandenes funktion som tegn med konventionelle betydninger. ${ }^{8}$ Den ene vinkel udelukker ikke nødvendigvis den anden, og under alle omstændigheder er det en pointe, at betydningen findes ved genstandene uafhængigt af den omtale, de måtte blive til del, selv om tilegnelsen af tingenes betydninger kan afhænge af kulturelt betingede koder.

Studiet af materialkultur åbner et væsentligt heuristisk perspektiv for studiet af romersk kultur som kontekst for Acta. Hvor hidtidige behandlinger har identificeret denne kontekst som tekstbåret materiale, f.eks. litterære eller historiografiske fremstillinger, forskydes interessen her i retning af materielt materiale. Ved at rette opmærksomheden mod bygninger og kunstværker som kontekst for centrale passager i Acta og ved at sætte fokus på Lukas' brug af begrebet "vejen” bevæger man sig som fortolker ud i skriftets materialkulturelle kontekst, når man søger at uddrage de betydninger, som de pågældende elementer kan have haft for skriftets oprindelige læser. Hvis betydningerne kan spores, rejser det spørgsmålet om deres funktion i Actas handlingsforløb, med Walaskay forstået som missionens udbredelse på romersk territorium. Antagelsen af at missionen foregår "ad ro-

7. Jules D. Prown, "Material/Culture: Can the Farmer and the Cowman Still be Friends?", Learning from Things: Method and Theory of Material Culture Studies, red. W. David Kingery (Washington \& London: Smithsonian Institution Press 1996), 19-27.

8. F.eks. Carl Knappett, Thinking Through Material Culture: An Interdisciplinary Perspective (Philadelphia: University of Pennsylvania Press 2005), 85-106 
mervej" skal ikke forstås sådan, at den er forenelig med bestående magtinstanser eller politiske og kulturelle institutioner i imperiet, blot at den benytter sig af dem under sin udbredelse. Det er på denne måde, romersk materialkultur præger betydningsdannelsen i skriftet, men denne accept af imperiets materialkulturelle betegnere er selvfølgelig af en anden art end den politisk orienterede apologi, som Walaskay har fremlæst. Forskellen består i den måde, hvorpå kulturelle institutioner repræsenterede romersk herredømme symbolsk, mens de konkrete magtudøvere repræsenterede det funktionelt. Sagt på en anden måde: Kulturen anskueliggjorde det romerske hegemoni, mens magtinstanserne var dette hegemoni.

\section{Missionen som territoriedannelse: Byer og provinser}

I Luke Timothy Johnsons kommentar til Acta fremhæves det gentagne gange, at missionens udbredelse fra øst mod vest skriftet igennem kan forstås som en gradvis udvidelse af kirkens territorium (Johnson 1992, første gang 11). Andre eksegeter har underbygget denne fortolkning ved hjælp af parallelle antikke kilder, der tyder på, at skriftet kan læses som en fortælling om kirkegrundlæggelse-som-kolonisering eller om generel geografisk ekspansion. ${ }^{9}$ Vernon K. Robbins sammenfatter dette tema ved at slå fast, at "[...] Luke and Acts present a strategy of territoriality." 10 Kirkens territoriedannelse som tema i Acta slås an af det markante og særegne opbud af stednavne i skriftet som helhed. ${ }^{11}$ Her er forløbet i kap. 16-20 eksemplarisk. Ligesom det er tilfældet med Paulus' forudgående missionsvirksomhed, former redegørelsen for hans missionsrejser i de romerske provinser Makedonien, Achaia og Asia i disse kapitler sig i høj grad som fortløbende ophold i forskellige byer i de pågældende områder. Geografisk lokalitet og udstrækning spiller altså en særlig rolle her: Som byer, hvori

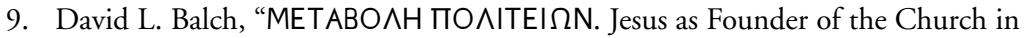
Luke-Acts: Form and Function", Contextualizing Acts: Lukan Narrative and Greco-Roman Discourse, red. Todd Penner \& Caroline Vander Stichele (Society of Biblical Literature Symposium Series 20. Atlanta: Society of Biblical Literature 2003), 233-56. Walter T. Wilson, "Urban Legends: Acts 10:1-11.18 and the Strategies of Greco-Roman Foundation Narratives", JBL 120, 1 (2001), 77-99.

10. Vernon K. Robbins, "Luke-Acts: A Mixed Population Seeks a Home in the Roman Empire", Images of Empire, red. L. Alexander, JSOTSup 122 (Sheffield: Sheffield Academic Press 1991), 202-21 (202).

11. Loveday Alexander, "Narrative Maps: Reflections on the Toponymy of Acts", The Bible in Human Society: Essays in Honour of John Rogerson, JSOTSup 200, red. Carroll, Cline \& Davies (Sheffield: Sheffield Academic Press 1995), 17-57, (40f.). 
missionen finder sted (f.eks. 18,1); som provinser eller landområder, der gennemrejses, eller hvori byerne ligger (f.eks. 16,6-8); eller blot som navngivne steder, der passeres (f.eks. 17,1). Det bliver på den måde tydeligt, at der vindes nye områder for kirken under rejserne.

Den retningsgivende præmis for denne udbredelse af kirkens territorium er formuleret i Jesus' missionspålæg i kapitel 1,8: "men I skal modtage kraft, idet den hellige ånd kommer over jer, og I skal være mine vidner i Jerusalem og i hele Judæa og Samaria og indtil jordens yderste." Der er tale om et universelt missionsopdrag, og de udpegede områder giver missionen et geografisk perspektiv, som snart efter understøttes ved brugen af en konventionel romersk kode for samhørighed mellem etniske grupper og den lokalitet, de bebor. Denne territorialt orienterede kode fremmanes under pinseunderet, hvor apostlenes beherskelse af alverdens sprog efter modtagelsen af den lovede "hellige ånd" bevidnes af diasporajøder, som befinder sig i Jerusalem og her repræsenterer alle nationer som missionens modtagere. Det opremses, at denne gruppe består af "Parthere og Medere og Elamitter og de, som bebor Mesopotamien, Judæa, Kappadokien, Pontus og Asien, Frygien såvel som Pamfylien, Ægypten og egnene i Libyen ved Kyrene, og de, som er hjemmehørende i Rom, jøder og proselytter, kretensere og arabere" (2,9-11). Opremsningen følger romerske konventioner for beskrivelse af imperial magt ved hjælp af såkaldte "nationsfortegnelser", en liste over nationer eller folkeslag, som Rom eller en romersk imperator havde underlagt sig. Under Augustus blev nationsfortegnelser placeret $\mathrm{i}$ bygninger og i litterære værker for at betegne det territorium, kejseren havde samlet under sig. Fortegnelser af denne art benævnte bestemte geografiske lokaliteter såvel som folkeslag, der kendetegnede andre lokaliteter, for at give en oversigt over summen af undertvungne regioner. Her anvender Lukas denne topos til at beskrive hele verden som kirkens kommende territorium, der står foran at underlægges af Gud gennem missionen. ${ }^{12}$

\section{Anneksionen af Athen og Efesos}

Handlingen i kapitlerne 16-20, hvor kirken etableres i de romerske provinser Makedonien, Achaia og Asia, falder dermed i tråd med Actas indledende bestemmelse af en universel missionsmark. I kap. 17 er Paulus' missionsvirksomhed nået til Athen, hvor han grundlægger

12. Nationsfortegnelser: Claude Nicolet, Space, Geography, and Politics in the Early Roman Empire (Ann Arbor: The University of Michigan Press 1991), 19-22, 47. Lukas' brug heraf: Gary Gilbert, "Roman Propaganda and Christian Identity in the Worldview of Luke-Acts”, Penner \& Stichele (2003), 252. 
en ny menighed. Eksegeter har hæftet sig ved, at Lukas med sin beskrivelse af byen har givet et rammende, kortfattet signalement af byens særlige topografisk-kulturelle fremtoning, bl.a ved at lade dette særpræg fremgå af Areopagostalen. ${ }^{13} \mathrm{Ved}$ at nævne Athens gudebilleder som et af byens kendetegn er Lukas i overensstemmelse med geograferne Pausanias og Strabon, som dog ikke omtaler et alter til "den ukendte gud" $(17,23)$, men Paulus' placering af denne kult inden for rammerne af en alsidig lokal religiøs praksis svarer til de to geografers beskrivelser. ${ }^{14}$ I sin tale "besætter" Paulus denne guds sted med den kristne Gud, forstået sådan at han omtolker denne guddom fra at være en gud, som athenienserne ærer på linje med andre, til at være hans egen monoteistiske Gud. Ikke alene fortrænger Paulus' Gud dermed atheniensernes "ukendte gud", men det betones implicit, at forestillingen om denne ene Gud ikke er forenelig med tanken om andre guder (v. 23-31).

"Indtagelsen" af Athen foregår altså gennem en symbolsk appropriation af byens gudebilleder. I øvrigt udgør geografi og territorium et delemne i Areopagostalen, fordi Paulus nævner, at de enkelte nationers territorier er fastsat af Gud, som også skal dømme samtlige om-

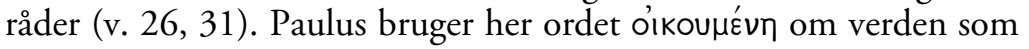
et overnationalt territorium, der tilhører Gud.

Spørgsmålet om territorium er også centralt hos Pausanias, hvis Rundforer til Grakenland menes at være blevet til ca. 160-173, godt et halvt århundrede efter Acta. Et delanliggende med Pausanias' omfattende værk demonstreres i William Huttons nylige fortolkning at have været definitionen af en oppositionel national identitet $\mathrm{i}$ et symbolsk opgør med romersk fremmedherredømme i Grækenland. ${ }^{15}$ Oppositionen kommer i stand ved beskrivelsen af et særligt græsk (ikke-romersk) territorium, hvis religiøse og kulturelle kendetegn afgrænses fra romersk kultur. Det græske område betragtes som define-

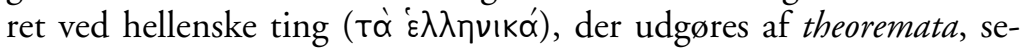
værdigheder såsom arkitektur, kunstværker eller naturgenstande, hvortil der knytter sig særlige logoi, dvs. myter eller historiske fortællinger, der drejer sig om det oprindelige, før-romerske Grækenland.

13. F.eks. Stephen G. Wilson, The Gentiles and the Gentile Mission in Luke-Acts (Cambridge: Cambridge University Press 1973), 196-218.

14. Pausanias, Description of Greece (LCL, Cambridge, Mass.: Harvard University Press 1969), I, XVII, 1. Strabo, The Geography of Strabo (LCL, Cambridge, Mass.: Harvard University Press 1970), IX.

15. William Hutton, Describing Greece: Landscape and Literature in the Periegesis of Pausanias (Cambridge: Cambridge University Press 2005), 42f. Hutton understreger (47f.), at denne "linje" hos Pausanias ikke er entydig, men suppleres af positive vurderinger af den romerske indsats i Grækenland, f.eks. Hadrians byggeprojekter. 
Det græske landskab fremstår derved som en konkretisering af særegne mytiske og historiske traditioner, uden at der eksplicit rettes kritik mod romerne. Ved fortielser, udeladelser o.lign. fortrænges den romerske tilstedeværelses materielle og kulturelle vidnesbyrd i Grækenland fra teksten, mens græsk kultur fremstår som dominerende i det græske kerneland (Hutton 2008, 312). Den konkrete gestaltning af det græske territorium former sig som en bevægelse mellem centre i de græske områder, især de traditionelle landsdeles hovedstæder, og fra disse centre foretager Pausanias i teksten ekskursioner ud i landet til vigtige seværdigheder. De vigtigste byer beskrives efter samme princip, idet der begyndes med det "gamle" Grækenlands kulturelle centrum, Athen: De væsentligste bygninger, steder, helligdomme og kunstværker omtales, idet forfatteren tager udgangspunkt i hver bys centrale seværdighed. Grækenland fremstår som summen af særligt græske theoremata, til hvilke der knytter sig særligt græske logoi.

Med udgangspunkt i Huttons fortolkning af Pausanias skulle det derfor være muligt at beskrive missionsvirksomheden i f.eks. Achaia i Acta fra en ny vinkel. Lukas' beskrivelse af Paulus' anneksion af Achaia - eller for den sags skyld Makedonien eller Asia - følger Pausanias' forestilling om, hvad der karakteriserer et territorium strukturelt: Det er ved indtagelsen af centre som Athen, at evangeliet udbredes til de nye områder i deres helhed. I selve Athen er det da også ved invasion af et par af byens centrale lokaliteter, Agora og Areopagos $(17,17.19$; begge optræder som illustre atheniensiske steder hos Pausanias: XVII, 1; XXVIII,5), at missionen vinder fodfæste i byen. Denne "erobring" af nyt område skal forstås sådan, at missionen kommer til stede på den ny lokalitet, men selvfølgelig ikke sådan, at alle omvendes, eller at missionen med ét når ud til periferien af den annekterede missionsmark.

Territoriet tilføres sin identitet ud fra et centrum; Achaia ud fra Athen, Athen ud fra sine centrale steder, på samme måde som det græske territorium hos Pausanias gives sin identitet ud fra bestemte byer, og ligesom byerne får identitet ud fra deres theoremata. Til gengæld adskiller måden, hvorpå territoriet erhverver sin religiøse identitet hos Lukas, sig fra Pausanias' strategi for identifikation af det græske territoriums kulturelle identitet, for hvor Pausanias ser bort fra romersk materialkultur, suspenderer Lukas' Paulus jo eksplicit de stedlige gudebilleder og et enkelt monuments ikonografi omgøres radikalt. For som sagt angriber Paulus under sin afgørende tale byens kultiske praksis og billeder, dvs. atheniensiske theoremata, ved at redefinere et af dem, den ukendte guds alter, som et theorema, hvis ledsagende logos er fortællingen om den kristne Gud. Hvis Pausanias' subversive strategi går ud på at "se hen over" romerske monumenter $\mathrm{i}$ 
det græske landskab, drejer Paulus' sig i stedet om at se det udvalgte theorema i lyset af den kristne logos for derved at suspendere de atheniensiske guddomme og deres theoremata.

Pausanias'ske principper for karakterisering af et territorium ved hjælp af centrale theoremata og tilknyttede logoi genfindes i kapitlerne om kristendommens etablering i Efesos (18,24-19,40). Men Lukas leverer her en vigtig tilføjelse til sin territorieforståelse, idet beskrivelsen af missionens territoriale ekspansion anskues inden for rammerne

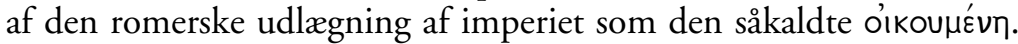
Før jeg analyserer denne forankring, skal jeg dog godtgøre, at territorietemaet er på spil i denne del af Acta.

Efesos omtales selvfølgelig ikke hos Pausanias, som koncentrerer sig om græsk kerneland, men Strabon har beskrevet byen knap halvandet hundrede år tidligere, hvor Augustus havde gjort den til hovedstad i provinsen Asia. Byens Artemistempel nævnes her som dens væsentligste kendetegn, og af andre vidnesbyrd fremgår det, at byen indeholdt flere betydningsfulde monumentalbygninger, heriblandt et teater, som også nævnes af Lukas (19,31) (Strabo: 14.1.22ff.). ${ }^{16}$ Der er tale om detaljer, som bidrager til en troværdig gengivelse af Efesos som særlig lokalitet. Ligeledes omtales Artemis som "stor" og "efesernes Artemis" $(19,28)$ i overensstemmelse med den lokale bekendelsesformular, ligesom sølvsmedenes tilstedeværelse alluderer til brugen af afgudsbilleder i forbindelse med kulten (Trebilco 2004, 22, 27f.). Kultbilledet og dets mytologi definerer altså Efesos.

Nyere eksegese af begivenhedsforløbet i forbindelse med Paulus' kirkegrundlæggelse i Efesos - og dermed i hele provinsen Asia (jf. 19,10) - lægger vægt på analogier mellem Lukasskrifterne på den ene side og græsk-romerske fortællinger om grundlæggelser af bystater og kolonier på den anden (Balch 2003, passim.). Den omfattende argumentation lader sig ikke referere meningsfuldt i kort form, så her skal den konklusion, som drages af den pågældende eksegese blot sammenfattes, nemlig at kirkekonstitutionen i Efesos hos Lukas ligner en grundlæggelse af en bystat eller en koloni, sådan at teksten også drejer sig om territorial ekspansion.

I Athen har kristendommens indtog medført et opgør med byens theoremata, dens gudebilleder og templer, og i Efesos afstedkommer Paulus' kirkegrundlæggelse en reaktion fra tilhængere af Artemis-kultens gudebillede (19,23-40). Sølvsmede anstifter et opløb vendt mod Paulus og hans disciple, fordi de er foruroligede over det store antal omvendte og over hans afvisning af, at gudebilleder er guder; et syns-

16. Cf. Paul Trebilco, The Early Christians in Ephesus from Paul to Ignatius, WUNT 166 (Tübingen: Mohr Siebeck 2004), 11-52. 
punkt, han allerede har fremført i Athen $(17,29)$. Angiveligt truer dette Artemis-kulten, og derfor hidses en folkemængde op og fører repræsentanter for den ny tro ind i teatret, hvor byens rådsforsamling efter to timers tilråb får dæmpet gemytterne. Der er selvfølgelig ikke tale om noget opgør mellem kirken og de romerske myndigheder, men episoden demonstrerer alligevel kirkens politisk kontroversielle status, sådan som Richard Cassidy har påpeget. Den er en gentagelse af urolighederne i Thessalonika (17,5-9), hvor jøder skabte tumult pga. Paulus' virksomhed og førte hans tilhængere for byens myndigheder med anklager om, at de kristne 1) "har sat den romerske verden i oprør", 2) "handler mod kejserens befalinger", og 3) "siger, at en anden er konge, Jesus". Beskrivelsen af det kristne projekt er sådan set korrekt; i hvert fald anskueliggør begivenhedsforløbet, at den paulinske missions vedvarende udmøntning i tumult udgør en trussel mod stabiliteten - lov og orden - i de romerske provinser, og i den forstand sætter kirken "den romerske verden i oprør" (Cassidy 1987, 90, 121).

Det udtryk, der her anvendes om verden, er óıkoupévn, som også bruges af Paulus om verden som Guds territorium i 17,31. Fra og med Augustus blev dette begrebs betydning betinget af hans erobringskrige og administrative nyordning af riget. Af eksempelvis Augustus' egen nationsfortegnelse i de selvbiografiske Res gestae fremgår det, at riget nu strakte sig over hele den civiliserede verden, og til denne forestilling om en altomfattende romersk magtsfære knyttede Augustus og hans eftertid en idé om, at Rom havde bibragt verden fred, harmoni og retstilstande (Nicolet 1991, 19, 192). I forbindelse hermed havde Augustus gjort kejsermagten i Rom til ubestridt centrum for hele rigets politisk-administrative liv, så efter Augustus ville det altså være en nødvendig betingelse at nå Rom for at nå "jordens yderste" $(1,8)$. Den augustæiske forståelse af óikounévn ses bl.a. hos Strabon, hvor beskrivelsen af Efesos kan tjene som eksempel: Augustus' genopbygning af byer i Asia omtales, og det nævnes, at han har fjernet kriminaliteten fra Efesos, hvor den førhen florerede ved Artemis-templet, fordi kriminelle kunne søge tilflugt her. ${ }^{17}$

I Acta anvendes óıkounévn-begrebet ud over i 17,6 bl.a. i 19,27,

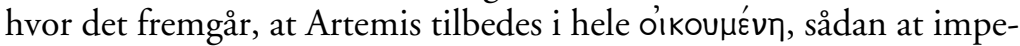
rium og Artemis-dyrkelse knyttes sammen. Missionsvirksomheden skildres dermed af en repræsentant for Efesos som stridende med romerriget, fordi den udfordrer den stedlige kult. I Areopagostalen har

17. Strabons politiske loyalitet fremlæses af Daniela Dueck, Strabo of Amasia: A Greek Man of Letters in Augustan Rome (London \& New York: Routledge 2000), $98 \mathrm{f}$. 
Paulus netop anfægtet dyrkelsen af gudebilleder, så det er korrekt at udlægge kristendommen som en religiøs praksis, som afviger fra det

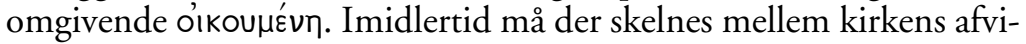
gelse fra verdensordenen på den ene side og Lukas' fremstilling af dens forhold til imperiets institutioner og magtinstanser på den anden, for som eksegeter samstemmende anfører, fremfører Lukas' kristne intetsteds i Acta nogen kritik af romerriget eller dets repræsentanter (f.eks. Cassidy 1987, 119). I overensstemmelse med skriftets funktion som apologia pro imperio tjener romerske embedsmænd og administration ofte til at befordre missionen, f.eks. da romernes retssystem mod slutningen bogstaveligt talt bringer forkyndelsen (Paulus) til Rom.

Missionen lægger altså ikke eksplicit afstand til den romerske verdensorden, selv om modstandere i Efesos siger det modsatte; snarere betjener den sig af politiske og kulturelle institutioner under sit virke. Konsistent med sin fremstilling af romerriget som "ramme" om udbredelsen af kirken anvender Lukas konsekvent dets administrative

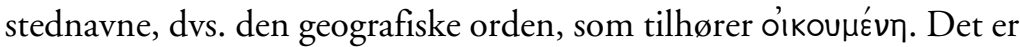
værd at bemærke, for hvor Pausanias i sin Rundfører markerer sin modstand mod Rom ved at ignorere romernes administrative grænsedragning omkring provinsen Achaia og i stedet benytte traditionelle områdebetegnelser, bruger Lukas løbende de romerske navne, og Paulus anvender netop provinsernes hovedstæder (f.eks. Thessalonika, Korinth og Efesos) som udgangspunkt for missionen. Generelt foregår kirkens territoriedannelse ved grundlæggelse af menigheder i politisk-kulturelle og religiøse centre i de respektive provinser. Såvel i Athen som i Efesos implicerer kirkens udbredelse en symbolsk appropriering af eller fortrængning af stedets topografiske særkende, dets theoremata. Men selv om de romerske provinser annekteres til kirkens territorium, anfægtes deres status som hovedstæder i imperiale provinser ikke.

\section{Vejen i imperiet}

Jeg har hidtil i artiklen beskæftiget mig med den måde, hvorpå materialkultur optræder $i$ Lukas' skrift, og med dens betydninger i denne rolle. Mit fokus i den følgende del vil snarere rette sig mod materialkultur som kontekst for skriftet. Det er i denne egenskab, romervejen udgør den betydningsgivende sammenhæng for Lukas' brug af ordet "vej" i Acta, idet denne brug dog formidles af vej-motivet i kapitlerne 8 og 9. Efter at have redegjort for romervejens materialkulturelle betydning og Lukas' forudsætninger for brugen af ordet vej i LXX, vil 
jeg derfor fremlægge en fortolkning af ApG 8,26-40 og af betydningen af ordet "vej" i Acta.

Et centralt politisk og kulturelt betydningsbærende træk ved de store romerveje, viae publicae, sådan som det på det seneste er blevet beskrevet fra historiografisk og arkæologisk hold, var deres funktion som betegnere af territorium. De kejserlige vejanlæg var bygget ud fra samme rumforståelse og principper for territorialt hegemoni, som allerede senrepublikkens vejanlæg havde været det. Periodens geografikundskaber førte til en forståelse af geografisk rum som opdelt i geometriske enheder af en vis størrelse, hvis ydre grænser ganske vist kunne være uklare, men hvis udstrækning mellem to eller flere tilsvarende enheder kunne defineres og anskueliggøres ved f.eks. vejanlæg, mener bl.a. Nicholas Purcell: "The geometric layout of the lands is measured, expressed and controlled by the celebration of the itineraries across them. The formation of such axes becomes a familiar aspect of Roman attitudes to the empire, almost to the point of being a doctrine." 18 Man kunne f.eks. markere et romersk rum ved at forbinde et vagt defineret "vestromersk" område med et tilsvarende "østromersk" ved hjælp af et vejanlæg som Via Egnatia. Denne måde at definere et territoriums udstrækning på suppleredes af vejens funktion som forbindelsesåre mellem romerske coloniae (Laurence 1999, 23ff.). Vejene blev typisk anlagt aksialt (bl.a. heraf deres funktion som indikator for rumlig udstrækning), og de forbandt ved deres forløb romerske bosættelser i det territorium, de beskrev.

Romervejens betydning i kejserdømmet var dog også tæt knyttet til kejserens person. Den rejsende blev konstant mindet om kejseren som patron, fordi alle veje var forsynet med milesten, som for hver mil med inskriptioner hyldede kejseren for konstruktionen eller istandsættelsen af vejen. De fremhævedes af, at intet andet måtte opføres mindre end tre meter fra vejsiden. Ved anlæggelse eller vedligeholdelse af veje videreførte kejserne en tradition fra republikansk tid for disse aktiviteter som opretholdende for rigets territoriale samhørighed og definerende for dets rum. Strabon fremhæver således Augustus' vejanlæg som forudsætning for hans o'ikoupévn (Strabo: 4.6.6; Drueck 2000, 99). De allestedsnærværende milesten blev suppleret af billeder og monumenter, som repræsenterede kejseren, og som knyttede ham visuelt eller symbolsk sammen med vejen. Ifølge Ray Laurence skabte vejene som territoriale markører et politisk rum,

18. Nicholas Purcell, "The Creation of Provincial Landscape: the Roman Impact on Cisalpine Gaul", The Early Roman Empire in the West, red. T. Blagg \& Martin Millett (Oxford: Oxbow Books 1990), 7-29 (13). 
hvis identitet som kejserdømme anskueliggjordes ved de mange sten og monumenter $(2005,57)$.

Det er da også sådan, vejen afgiver betydning i Statius' hyldestdigt Via Domitiana om Domitians nyanlagte vej i Campanien. Kejseren har forbundet fjerntliggende områder ad en direkte, "aksial" rute, som erstatter de hidtidige, snoede stier. ${ }^{19}$ Han har betvunget skove og bjerge, og Statius lader floden Vulturnus, som nu flyder tæmmet under en bro, erkende sit nederlag til kejseren og hans vejteknologiske triumf (Statius: IV.III,65-90). Det sker i en direkte henvendelse, hvor flodguden på én gang taler til Via Domitiana på broen hen over sig og til kejseren selv, så den triumferende kejser deler identitet med sin vej som betvinger af den personificerede flod.

For Lukas' oprindelige læsere har der altså knyttet sig materialkulturelt betingede konnotationer til ordet "vej". Selv om Lukas undlader at benævne specifikke romerveje, som missionen må have gjort brug af for at udbrede kirken i det østromerske område, optræder "vejen" som begreb som et ledemotiv i Acta, hvor det synes udspaltet i to anvendelser. ${ }^{20}$ For det første anvendes det som betegnelse for den særlige sammenslutning, en "sekt" $(24,14)$, som Paulus først forfølger og siden slutter sig til; her er der altså tale om et synonym for "de kristne" $(9,2 ; 19,23 ; 24,22)$. For det andet bruges det i overført forstand til at betegne indholdet og karakteren af den kristne forkyndelse, det som evangeliet omhandler og bringer i stand: Der er tale om forkyndelse, som har vejen til frelse som emne, og denne forkyndelse forvaltes af bevægelsen ved navn Vejen, som derfor er frelsende mission. Om Apollos i Korinth hedder det således, at "han var undervist om Herrens vej, og sprudlende af ånden talte og underviste han nøjagtigt om ting vedrørende Jesus" $(18,25)$, sådan at forkyndelse som indhold og aktivitet optræder sammenhængende. Da troldmanden Elymas i Pafos forsøger at forhindre den romerske statsholder i at til-

19. Statius, "Via Domitiana", Silvae (LCL, London \& Cambridge, Mass.: Harvard University Press 1967), 216-28 (IV.III,65-90).

20. Ifølge Loveday Alexander er rejsen Actas handlingsmæssige plot, forstået som evangeliets systematiske udbredelse fra Jerusalem over det østlige romerrige mod Rom. Loveday Alexander, "In Journeyings Often': Voyaging in the Acts of the Apostles and in Greek Romance", Library of New Testament Studies 298. Acts in Its Ancient Literary Context: A Classicist Looks at the Acts of the Apostles (London: T\&T Clark International 2005), 69-96 (73). Der foreligger dog identifikationer af enkelte romerveje, som Lukas' samtidige læser vil have kunnet slutte sig til at Paulus benytter, se David French, "Acts and the Roman Roads of Asia Minor", The Books of Acts in Its Graeco-Roman Setting, 2, red. D.W.J. Gill \& Conrad Gempf (Grand Rapids, Mich.: The Paternoster Press 1994), 50-8. Johnson (1992), 305. "Vejens" to hovedbetydninger: Wilhelm Michaelis, ódós, ThWNT 5, 42-101 (93-5). 
egne sig Vejens tro, præciserer Paulus i sit udfald mod ham: "fjende af enhver retfærdighed, vil du ikke høre op med at bringe Herrens veje, de retlinede, i uorden?" $(13,10)$.

En forudsætning for denne forståelse af ordet "vej" som en metafor til beskrivelse af religionen som frelsesbetingelse findes i LXXs brug af samme begreb som betegnelse for frelsende livsførelse. I eksempelvis Sl. 118 identificeres den frelsende vej gentagne gange med budene i loven (v. 1-2; 94). Stanislas Lyonnet peger på, at der i denne skriftgruppe er en tendens til, at den frelsende vej både betegner livsførelse i henhold til budene og identificeres med Gud selv. ${ }^{21}$ Ifølge Lyonnet er denne identifikation af Gud med frelsens vej også indlejret i forståelsen af begrebet "vej” i Lukas' forstand som frelsende forkyndelse, der udfoldes inden for Vejen som bevægelse. Han peger overbevisende på, at Paulus' forfølgelse af tilhængere af Vejen, hvis navn han selvfølgelig anser for afledt af bevægelsens selvforståelse som en manifestation af Guds frelsesplan, i Jesus' henvendelse til Paulus i 9,4-5 beskrives som en forfølgelse af Jesus selv (Lyonnet 1981, 150, 162). Vejen optræder som identisk med Jesus, der på sin side identificeres som Paulus' "Herre" (f.eks. 26,15).

Når ordet "vej” i LXX kan identificeres som en forudsætning for brugen af det tilsvarende udtryk i Acta, er der tale om beskrivelse af en tekstbåren sammenhæng for Lukas' brug af ordet. Det forholder sig anderledes, når vejen som materiel genstand betragtes som kontekst for denne brug, idet man da beskriver ordets materialkulturelle kontekst. I betragtning af den centrale betydning, som begrebet "vej" og dets afledte brug som betegnelse for den kristne bevægelse har i Acta, fylder vejen som scene for begivenheder bemærkelsesværdigt lidt i skriftet. En markant undtagelse udgøres af Filips omvendelse af den etiopiske skatmester (hofmand) i 8,26-40. Lukas insisterer her på vejen som en omstændighed omkring skatmesterens omvendelse, og først herefter anvender han ordet "vej" som betegnelse for den kristne bevægelse og dens missionsbudskab. Med denne passage - og med den tilgrænsende beskrivelse af Paulus' omvendelse i kap. 9 - slår Lukas én gang for alle fast, at ordet "vej" som betegnelse for missionens forkyndelse og sociale gruppering henter sin betydning fra en konkret, materiel genstand, fra vejen som vej.

Begivenhederne i kap. 8 finder sted, mens de to aktører bevæger sig ad vejen fra Jerusalem til Gaza, som læsere med datidige erfaringer formentlig vil have opfattet som konstruktionsmæssigt velkonsolide- 
ret, når vogne som hofmandens kunne køre ad den (v. 28).22 Det er

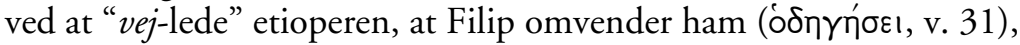
og efter omvendelsen begiver denne sig lykkelig "ad sin vej" (v. 39). Netop vejens iøjnefaldende rolle som en konkret omstændighed omkring omvendelsen inviterer læseren til at sammenligne denne episode med Paulus' omvendelse, Lukas' følgende delfortælling i kap. 9. Der er her egentlig tale om en fortælling, som "afbrydes" af beretningen om Filips missionsvirksomhed og omvendelse af den etiopiske hofmand, for 8,1-3 drejer sig om Paulus' forfølgelse af kirken i Jerusalem, en forfølgelse, som ifølge 9,2 skal udvides til at omfatte Vejen i Damaskus. Resultatet af Paulus' rejse bliver som bekendt diametralt modsat: Han tilslutter sig Vejen (de kristne) dér efter en omvendelse undervejs til byen. Ganske vist nævnes det først mod slutningen af omvendelsespassagen, at han er blevet omvendt på vejen ("vejen, ad hvilken du kom", v. 17, cf. v. 27), men stedet for omvendelsen, en vej, knytter fortællingen sammen med Filips omvendelse af etioperen. Ligheden mellem de to episoder forstærkes ved, at Filips "vejledning", som foregår i overført forstand, eftergøres bogstaveligt, da Paulus må lade sig føre ved hånden til Damaskus efter at være blevet blændet af Jesus. Sammenknytningen af en passage, hvori Vejen for første gang i skriftet optræder som navn på den kristne bevægelse, og hvori vejen som frelsesplan manifesteres som Paulus' omvendelse, med en episode, hvori der på sin side både findes en konkret brug af vejen som scene for omvendelse og en metaforisk anvendelse af ordet "vej" i forbindelse med Filips eksegetiske vejledning, gør det muligt at spørge til vejens konnotationer i Acta - ikke som navn på en bevægelse, for leveregler eller for en frelsesplan, men som en materiel størrelse, til hvilken der har knyttet sig særlige betydninger for Lukas' oprindelige læserskare i romerriget. Begge de nævnte omvendelser finder jo sted på en vej.

I 8,26-40 lader vejen til at være lineær eller aksial. Der peges selvfølgelig ikke eksplicit på, at vejen snorligt forbinder to steder, men teksten får dens forløb til at fremstå sådan: Handlingen foregår på "vejen, som går ned fra Jerusalem til Gaza" (v. 26), og de to deltageres bevægelse ad vejen fremtræder som jævnt fremadskridende, ligesom etioperen til sidst "begav sig ad sin vej lykkelig" (v. 40). Også i kapitel 9 fremstilles vejen fra Jerusalem til Damaskus "aksialt", som to steder i rummet, der forbindes ved en rute, hvis forløb ikke beskrives nærmere (v. 2-3).

22. Ray Laurence, The Roads of Roman Italy: Mobility and Cultural Change (London: Routledge 1999), 138. 
Fremstillingen af vejen hos Lukas har derfor svaret til forståelsen af et centralt træk ved romervejens beskaffenhed og betydning. Filip vinder land for kirken under sin vejledning på vejen fra Jerusalem til Gaza, men det er også vigtigt at notere sig hans missionstriumf i v. 40, hvor han rejser fra Ashdod over en række byer til Cæsarea, hvis navn minder læseren om det romerske hegemoni. Han grundlægger menigheder, hvis placering på hans missionsakse giver mindelser om placeringen af romerske coloniae. Lukas lader altså vejen optræde på en måde, som svarer til den romerske brug af vejen som en markør af territorial udstrækning: I både kap. 8 og 9 markerer den således missionens indtog på aksen mellem Jerusalem og Gaza såvel som Jerusalem og Damaskus, mens Filips rute i kystlandet viser, at rummet dér nu er evangeliseret.

Som vi så, identificerer Lukas entydigt Jesus med Vejen, som Paulus forfølger. Ligesom kejseren, som i Acta kaldes "herre" af Porkius Festus $(25,26)$, i den romerske materialkultur og hos Statius repræsenteres af vejen som udsagn om imperialt hegemoni, identificeres Paulus' "herre", Kristus, med Vejen. Her præger den materielle romervejs beskaffenhed og tilhørende metaforik derfor dens betydning i Actas sammenhæng: Hvor den materielle via publica symbolsk manifesterede kejseren og hans territorium, var Vejen og dens udbredelse ensbetydende med frelsens territoriale ekspansion. "[...F]jende af al retfærdighed, vil du ikke høre op med at bringe Herrens veje, de retlinede, i uorden?", spørger Paulus som sagt troldmanden Elymas og lyder, som om han havde opsynet med en del af kejserens vejnet $(13,10)$. Læseren ved dog, at han er Jesus' curator viae. ${ }^{23}$

Når kejserens territoriale hegemoni kunne forbindes med vejen, hang det sammen med tilstedeværelsen af adskillige markører af hans magt langs vejen. Statius giver eksempler på denne prægning. Han beskriver både en triumfbue ved indledningen til Via Domitiana, og broen over floden Vulturnus er udsmykket med trofæer, sådan at de kejserlige monumenter og symboler tilfører vejen en særlig identitet: Vejen betegner ganske vist i sig selv et behersket territorium, men dets identitet (som kejserligt) ekspliciteres ved dens ledsagende symboler. Dermed bliver der tale om en måde at definere territorium på, som kan sammenlignes med Pausanias' strategi for definition af et særligt græsk område i Rundfører til Grakenland. Pausanias ser som sagt bort fra vidnesbyrd om romersk tilstedeværelse i Grækenland, og han knytter sine logoi til theoremata, som peger på specifik græsk mytologi og historie. Derved fremstår landskabet som græsk snarere end

23. Curatores viarum, se Tamas Pékary, Untersuchungen zu den römischen Reichsstrassen (Bonn: Rudolf Habelt 1968), 7. 
romersk. Statius forbinder derimod vejen som markør af romersk magt med kejseren gennem hans theoremata, dvs. hans monumenter.

Hvordan forholder det sig så med Lukas' fremstilling af vejen i sammenligning med henholdsvis Pausanias og Statius? Selv om han som bemærket gør brug af romerske koder for vejens gestaltning og symbolik, knytter han ingen romerske genstande (monumenter, milesten el.lign.) til vejen fra Jerusalem til Gaza. Vejen betegner ganske vist evangeliets rumlige ekspansion, men dens prægning er ikke kejserlig. Den vel nok eneste identitetsskabende markør, Lukas anvender ved vejen, er "noget vand", som etioperen og Filip passerer, og hvor etioperen lader sig døbe. Vandet tager dermed det kejserlige theoremas plads. Ligesom kejserlige milesten indikerede, at vejen repræsenterede kejseren, viser vandet her, at vejen er Vejens - altså Jesus'. Det i sig selv ret upåfaldende vand bidrager til at lade vejen betegne et specifikt territorium, som tilhører kirken: Den lineære vej til Gaza og fra Ashdod over kystlandets byer til Cæsarea beskriver den kristne bevægelses rum. Pointen får atter symbolsk form i 9,3, hvor Jesus manifesterer sin magt over ruten fra Jerusalem til Damaskus. Her henter vejen ikke sin identitet fra noget vand, men fra et lys i himlen.

\section{Konklusion: Materialkulturen i apologien for imperiet}

Hvis Lukas' tekst kan læses som en fremstilling af imperiets institutioner og repræsentanter som anvendelige for kristendommens udbredelse, er der derfor noget, der tyder på, at dets materialkultur indgår i forståelsen af, hvad imperiet er. Det sker på to niveauer i Acta: som genstande, der indgår i handlingen, eller som materialkulturelt betinget metaforik eller symbolik i teksten.

Det kristne territorium kommer i stand ved en indtagelse af byer $i$ Achaia og Asia gennem en omtolkning af deres theoremata ved hjælp af kristne logoi (Athen) eller en fortrængning af de stedlige theoremata (Efesos), sådan at genstande, som synekdokisk definerer kulturelle eller politiske centre i det romerske rige, er approprieret eller erstattet af den kristne religion. Til gengæld anfægtes de pågældende byer ikke som politisk-kulturelle centre, blot betegner de nu et nyt territorium - kirkens. Ganske vist trues Artemis-kulten i Efesos, som anerkendes af hele den romerske o'ikoupévn, angiveligt af Paulus' mission, men samtidig fungerer grundlæggelsen af kirken her som udgangspunkt for evangeliseringen af hele den romerske provins Asia, sådan at byens politiske betydning implicit anerkendes gennem missionen. Selv om vejen mellem byerne ikke nævnes eksplicit i denne del af Acta, er den på dette tidspunkt i teksten allerede omtolket til en missionsvej 
på en måde, som stemmer overens med konventionerne for sammenknytning af kejserens person og magtsfære med romervejen.

I Acta fremstår elementer af romerrigets materialkultur derfor som symbolske redskaber for missionens udbredelse. Athen og Efesos' respektive status af kulturelt eller politisk religiøst centrum udnyttes til at udbrede missionen. Samtidig udnyttes romervejens politiske metaforik til at markere, at kirken i forbindelse med efterlevelsen af sit oprindelige missionsopdrag er i færd med gradvist at indtage det romerske rum "indtil jordens yderste." 